\title{
Expression of UCP2 is associated with sensitivity to platinum-based chemotherapy for ovarian serous carcinoma
}

\author{
MASARU KAWANISHI, TAKESHI FUKUDA, MASAHIRO SHIMOMURA, YUTA INOUE, \\ TAKUMA WADA, REIKO TASAKA, TOMOYO YASUI and TOSHIYUKI SUMI
}

Department of Obstetrics and Gynecology, Osaka City University Graduate School of Medicine, Osaka 545-8585, Japan

Received September 16, 2017; Accepted April 16, 2018

DOI: $10.3892 / \mathrm{ol} .2018 .8598$

\begin{abstract}
The standard treatment for ovarian serous carcinoma is maximum debulking surgery and platinum-based chemotherapy. Despite the high response rate for chemotherapy, the majority of patients will be resistant to first-line agents and the prognosis for these patients is particularly poor. Currently there are no reliable methods to determine or predict platinum resistance. Uncoupling protein 2 (UCP2) is widely expressed in cancer cells and regulates the production of mitochondrial reactive oxygen species (ROS). A reduction in ROS is associated with carcinogenesis and chemoresistance. Downregulation of UCP2 significantly causes increased cell death following chemotherapy. The present study investigated the association between UCP2 expression and platinum sensitivity. The study included 54 patients with ovarian serous carcinoma (FIGO stages III and IV) who were treated at Osaka City University Hospital between January 2005 and December 2012. Patients were divided into a platinum-sensitive group $(n=27)$ and platinum-resistant group $(n=27)$ based on the platinum-free interval, which was calculated from the time of last platinum administration to the time of recurrence. UCP2 expression in human ovarian serous carcinoma cells was inhibited by genipin, and changes in carboplatin sensitivity were examined. The UCP2 weighted score was lower in the platinum-sensitive group than in the platinum resistant-group $(\mathrm{P}=0.005)$. In addition, patients in the low UCP 2 expression group were more sensitive to platinum-based chemotherapy than those in the high UCP2 expression group $(\mathrm{P}=0.001)$. Sensitivity to carboplatin was significantly increased when UCP2 was inhibited in human ovarian serous carcinoma cells in vitro. $\mathrm{UCP} 2$ expression may be a predictive marker of the
\end{abstract}

Correspondence to: Dr Takeshi Fukuda, Department of Obstetrics and Gynecology, Osaka City University Graduate School of Medicine, 1-4-3 Asahimachi, Osaka 545-8585, Japan

E-mail: takeshif@med.osaka-cu.ac.jp

Key words: ovarian serous carcinoma, uncoupling protein 2, chemotherapy, carboplatin, predictive marker efficacy of platinum-based chemotherapy for patients with ovarian serous carcinoma.

\section{Introduction}

Ovarian serous carcinoma is a common cause of cancer deaths in females worldwide $(1,2)$. Patients are generally diagnosed in an advanced stage of disease and have a high mortality rate (3). The standard treatment is maximum debulking surgery and platinum-based chemotherapy (4). Despite a high response rate for chemotherapy, the majority of patients will be resistant to first-line agents and these patients have a particularly poor prognosis (5). Platinum agents are key drugs in primary chemotherapy for patients with ovarian carcinoma, however, there are no clinical biomarkers that predict platinum sensitivity. At recurrence, the possibility of response to re-treatment with platinum-based chemotherapy depends on the platinum-free interval, which is calculated from the time of last platinum administration to the time of cancer recurrence (6). If the ovarian carcinoma recurs within 6 months from the last platinum administration it is considered to be 'platinum resistant', whereas if recurrence occurs more than 6 months after the last platinum administration it is considered to be 'platinum sensitive' (7). The sensitivity to platinum-based chemotherapy is an independent prognostic factor for overall and progression-free survival of patients with ovarian carcinoma (8). It is difficult to predict the sensitivity to platinum-based chemotherapy before the first recurrence therefore 'platinum-resistant' patients are identified retrospectively after recurrence of their cancer or failure to respond to initial platinum-based chemotherapy. Understanding the predictors of response to platinum-based chemotherapy will help us select sensitive patients for chemotherapy and spare resistant patients from the toxicity of platinum-based chemotherapy, and will also allow customization of treatments and clinical stratification of patients with ovarian carcinoma.

Currently, there are no reliable methods to determine or predict platinum sensitivity. To improve the prognosis of platinum-resistant ovarian serous carcinoma, the aim of this study was to find new biomarkers with prognostic and predictive potential and search for new therapeutic targets.

Reactive oxygen species (ROS) generated by chemotherapeutic agents that are able to evade antioxidant defenses cause cell damage and death (9-11). Uncoupling proteins 
(UCPs) are part of the superfamily of mitochondrial anion transporters $(12,13)$. There are five known types of UCP (UPC1 to UPC5) with varied characteristics and different tissue distribution (14). The superoxide from the mitochondrial inner membrane activates UCP2 and UCP3, and it can reduce ROS generation (15). UCP2 is broadly expressed in cancer cells and is able to suppress mitochondrial ROS production, in turn mitigating oxidative stress (16). Loss of UCP2 function can increase the production of ROS, while its overexpression may promote cytoprotection by mitigating oxidative stress $(17,18)$. Additionally, UCP2 advances carcinogenesis and chemoresistance (19-21). UCP2 is associated with human colon carcinogenesis $(22,23)$. Mitochondrial uncoupling by UCP2 induces resistance to gemcitabine in pancreatic cancer cells (19) and inhibition of UCP2 with genipin sensitizes cancer cells to chemotherapeutic agents (19-21). This evidence suggests that UCP2 is a potential target for cancer treatment with chemotherapeutic agents that promote oxidative stress. The expression of UCP2 and its association with sensitivity to platinum-based chemotherapy for ovarian serous carcinoma was investigated in this study.

\section{Materials and methods}

Patients and samples. The present study included 54 patients with ovarian serous carcinoma (FIGO stages III and IV). All patients were treated at Osaka City University Hospital (Osaka, Japan) from January 2005 to December 2012. Patients were divided into two groups based on recurrence of cancer within 6 months from the last platinum administration. Both groups underwent maximum debulking surgery followed by platinum-based chemotherapy. In the first group (platinum-sensitive group), disease did not recur within 6 months from the last platinum administration whereas in the second group (platinum resistant group), disease recurred within 6 months. Written informed consent was obtained from each patients prior to surgery. The study proposal was approved by the Institutional Review Board (IRB) of Osaka City University Hospital (IRB no. 3525).

Immunohistochemical staining. Immunohistochemical analysis was performed to examine UCP2 expression in paraffin-embedded sections using an anti-UCP2 antibody (cat. no. ab116263; Abcam, Cambridge, UK) and a Dako LSAB2 Peroxidase kit (cat. no. K0675; Agilent Technologies, Inc., Santa Clara, CA, USA). The paraffin-embedded sections (4 $\mu \mathrm{m}$-thick) were de-paraffinized, hydrated, and immersed in $3 \%$ hydrogen peroxide for $10 \mathrm{~min}$ at room temperature to block endogenous peroxidase activity. For antigen retrieval, sections were immersed in $10 \mathrm{mM}$ citrate buffer $(\mathrm{pH} 6.0$ ) and heated in an autoclave at $110^{\circ} \mathrm{C}$ for $20 \mathrm{~min}$. Then tissue sections were washed in PBS and incubated overnight at $4^{\circ} \mathrm{C}$ with a 1:100 dilution of the aforementioned rabbit polyclonal antibody for UCP2. Next, sections were washed in PBS for $15 \mathrm{~min}$ and incubated with biotinylated goat anti-rabbit immunoglobulin G (Dako; Agilent Technologies, Inc.) for $10 \mathrm{~min}$. After washed with PBS, sections were incubated with a streptavidin-peroxidase solution and 3,3'-diaminobenzidine was used as the chromogenic reagent. Finally, sections were counterstained with hematoxylin. The specificity of the immunohistochemical reactions was confirmed by omitting the primary antibody.

The immunohistochemical expression of UCP2 were assessed quantitatively according to the weighted score method of Sinicrope et al (24). Staining intensity was categorized into three classes: $1+$, weak; $2+$, moderate; and $3+$, intense. The mean percentage of stained tumor cells was classified as follows: $0, \leq 5 \% ; 1,5<$ and $<25 \% ; 2,25<$ and $<50 \% ; 3,50<$ and $<75 \%$; $4,>75 \%$. The weighted score was determined by multiplying the score of staining intensity for each tissue specimen by that of percentage of stained tumor cells.

Cell culture. The human ovarian serous carcinoma cell line OVSAHO (no. JCRB1046; National Institutes of Biomedical Innovation, Health and Nutrition, Osaka, Japan) was cultured in RPMI medium (Gibco; Thermo Fisher Scientific, Inc., Waltham, MA, USA) containing $10 \%$ fetal bovine serum (Gibco; Thermo Fisher Scientific, Inc.). Cells were cultured in a humidified $5 \% \mathrm{CO}_{2}$ atomosphere and at $37^{\circ} \mathrm{C}$.

Chemosensitivity assay. The sensitivity of cells to carboplatin was examined using a Cell Counting Kit-8 (CCK-8; Dojindo Molecular Technologies, Inc., Kumamoto, Japan). Cells were collected and seeded into a 96 -well tissue culture plate at a density of approximately $2 \times 10^{3}$ cells $/ \mathrm{ml}$. After $24 \mathrm{~h}$ the culture medium was replaced with $100 \mu \mathrm{l}$ of fresh medium per well and $10 \mu \mathrm{l}$ dimethyl sulfoxide (DMSO) alone or containing $50 \mu \mathrm{M}$ genipin (cat. no. G-4796; Sigma Aldrich, Missouri, USA) was added to each well. Cells were then treated with carboplatin $(10-1,000 \mu \mathrm{M})$ for $24 \mathrm{~h}$. At the end of treatment $10 \mu \mathrm{l} \mathrm{CCK}-8$ was added and the plates were incubated for $2 \mathrm{~h}$ before measurement of the absorbance at $450 \mathrm{~nm}$ with a microplate reader (Corona Electric Co., Ltd., Ibaraki, Japan). Dose-response graphs were constructed as the percentage of viable cells compared with the control cells.

RNA extraction and reverse transcription-quantitative polymerase chain reaction. Total RNA was extracted from the human ovarian serous carcinoma cell line OVSAHO using a RNeasy Mini kit (Qiagen GmbH, Hilden, Germany) and reverse transcribed into cDNA using a High Capacity cDNA Reverse Transcription Kit (Applied Biosystems; Thermo Fisher Scientific, Inc.). Gene expression of UCP2 was determined using a TaqMan Gene Expression Assay (Applied Biosystems; Thermo Fisher Scientific, Inc.) in the Applied Biosystems 7500 Fast Real-Time PCR System. For quantification, gene expression was normalized to that of $G A P D H$.

Statistical analysis. Statistical analyses were performed using SPSS software version 21.0 (IBM SPSS, Armonk, NY, USA). Data are presented as the mean \pm standard error in Figures and as the mean \pm standard deviation in Tables. Kaplan-Meier and log-rank analyses were performed to assess prognosis. Mann-Whitney U test was performed to compare the weighted scores. The differences between the means of two groups were assessed using Student's t-test, and associations of the categorical variables in two groups were assessed using $\chi^{2}$ tests. $\mathrm{P}<0.05$ was considered to indicate a statistically significant difference. 
Table I. Characteristics of patients in the platinum-sensitive and -resistant groups.

\begin{tabular}{|c|c|c|c|}
\hline Characteristics & Platinum sensitive $(\mathrm{n})$ & Platinum resistant (n) & P-value \\
\hline No. of patients & 27 & 27 & \\
\hline Age (years) & & & $0.725^{\mathrm{a}}$ \\
\hline Mean \pm SD & $61.0 \pm 12.2$ & $60.0 \pm 10.0$ & \\
\hline FIGO stage & & & $0.277^{\mathrm{b}}$ \\
\hline IIIA & 1 & 0 & \\
\hline IIIB & 3 & 1 & \\
\hline IIIC & 21 & 19 & \\
\hline IVA & 1 & 4 & \\
\hline IVB & 1 & 3 & \\
\hline Tumor marker & & & $0.374^{\mathrm{a}}$ \\
\hline CA125, U/ml (mean) & $3,343.3$ & $2,180.1$ & \\
\hline Postoperative residual disease & & & $0.004^{\mathrm{b}}$ \\
\hline None & 5 & 0 & \\
\hline$<1 \mathrm{~cm}$ & 10 & 4 & \\
\hline$>1 \mathrm{~cm}$ & 12 & 23 & \\
\hline
\end{tabular}

${ }^{a}$ Student's t-test. ${ }^{\mathrm{b}} \chi^{2}$ test. FIGO, International Federation of Gynecology and Obstetrics; SD, standard deviation.

Table II. Weighted scores for uncoupling protein 2 expression in the platinum-sensitive and -resistant groups.

\begin{tabular}{lcc}
\hline & \multicolumn{2}{c}{ No. of patients } \\
\cline { 2 - 3 } Weighted score & Platinum sensitive & Platinum resistant \\
\hline 0 & 2 & 1 \\
1 & 5 & 1 \\
2 & 3 & 1 \\
3 & 1 & 0 \\
4 & 1 & 2 \\
6 & 7 & 2 \\
8 & 4 & 12 \\
9 & 1 & 1 \\
12 & 3 & 7 \\
Total & 27 & 27 \\
Mean & 5.1 & 7.9 \\
\hline
\end{tabular}

\section{Results}

Patient characteristics. A total of 54 patients with ovarian serous carcinoma were divided into the platinum-sensitive group $(n=27)$ and the platinum-resistant group $(n=27)$. Table I shows age, FIGO stage, tumor marker, and post-surgery observations for the study patients. There were no significant differences in these parameters between the two groups other than postoperative residual disease.

UCP2 expression in ovarian serous carcinoma tissue. Cytoplasmic expression of UCP2 was observed in tumor cells (Fig. 1). Table II shows the UCP2 weighted scores in tissues

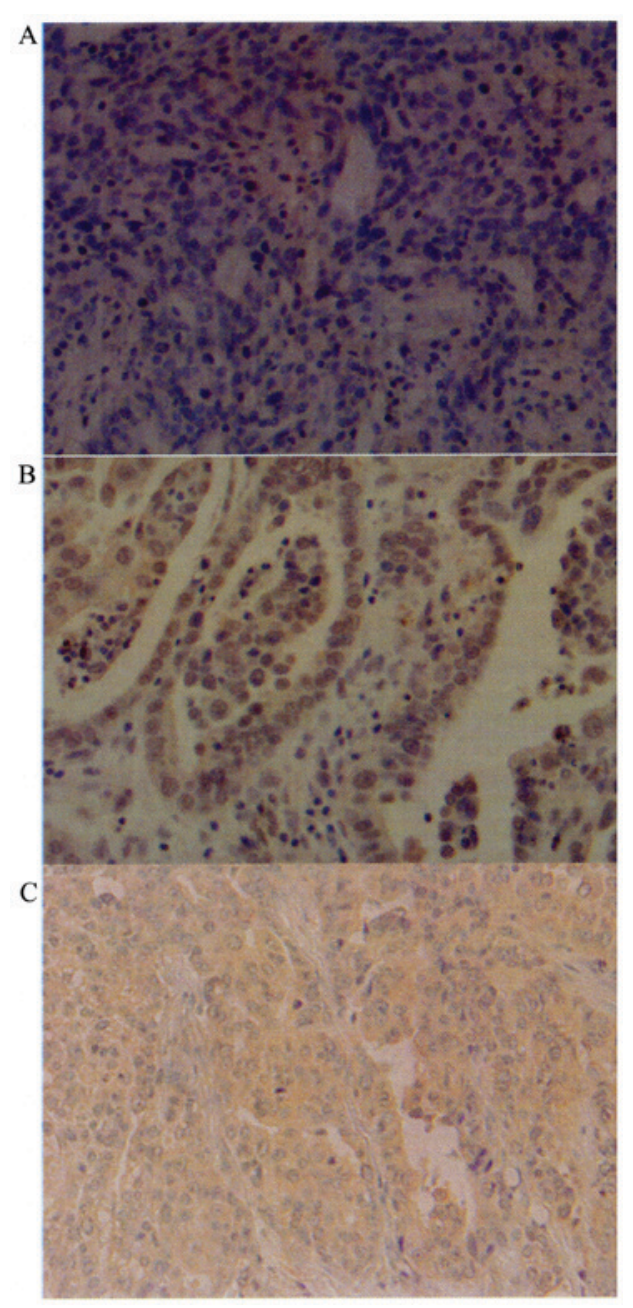

Figure 1. Immunohistochemical staining of UCP2 in ovarian serous carcinoma. (A) Negative control performed without primary antibody. Scores of (B) 6 and (C) 12 obtained in the presence of a primary antibody against UCP2. Hematoxylin staining. Magnification, x400. UCP2, uncoupling protein 2. 
Table III. Characteristics of patients in the low and high UCP2 expression groups.

\begin{tabular}{|c|c|c|c|}
\hline \multirow[b]{2}{*}{ Characteristics } & \multicolumn{2}{|c|}{ No. of patients } & \multirow[b]{2}{*}{ P-value } \\
\hline & Low UCP2 expression (score $\leq 6$ ) & High UCP2 expression (score $\geq 8$ ) & \\
\hline No. of patients & 26 & 28 & \\
\hline Age (years) & & & $0.610^{\mathrm{a}}$ \\
\hline Mean \pm SD & $61.3 \pm 11.1$ & $59.8 \pm 11.2$ & \\
\hline FIGO stage & & & $0.694^{\mathrm{b}}$ \\
\hline IIIA & 0 & 1 & \\
\hline IIIB & 3 & 1 & \\
\hline IIIC & 19 & 21 & \\
\hline IVA & 2 & 3 & \\
\hline IVB & 2 & 2 & \\
\hline Tumor marker & & & $0.566^{\mathrm{a}}$ \\
\hline CA125, U/ml (mean) & $3,156.7$ & $2,395.0$ & \\
\hline Tumor size (mm) & & & $0.144^{\mathrm{a}}$ \\
\hline Mean \pm SD & $46.9 \pm 17.2$ & $53.7 \pm 14.9$ & \\
\hline Postoperative residual disease & & & $0.005^{\mathrm{b}}$ \\
\hline None & 2 & 3 & \\
\hline$<1 \mathrm{~cm}$ & 12 & 2 & \\
\hline$>1 \mathrm{~cm}$ & 12 & 23 & \\
\hline
\end{tabular}

${ }^{a}$ Student's t-test. ${ }^{b} \chi^{2}$ test. UCP2, uncoupling protein 2; FIGO, International Federation of Gynecology and Obstetrics.

of the two patient groups. The mean weighted score for UCP2 expression was significantly lower in the platinum-sensitive group compared with the platinum-resistant group (5.1 and 7.9, respectively, $\mathrm{P}=0.005$; Table II and Fig. 2).

In continuation, cases were classified into two groups according to their UCP2 expression levels: the low UCP2 expression group (weighted score, 0-6) and the high UCP2 expression group (weighted score, 8-12). Table III shows the characteristics of the high and low expression groups, with analyses revealing no significant differences between the two groups other than postoperative residual disease.

Correlation of platinum sensitivity with UCP2 expression. Within the low UCP2 expression group, 19 cases $(73.1 \%)$ belonged to the platinum-sensitive group while 7 (26.9\%) belonged to the platinum-resistant group. In the high UCP2 expression group, 8 cases $(28.6 \%)$ belonged to the platinum-sensitive group and $20(71.4 \%)$ belonged to the platinum-resistant group. The low UCP2 expression group was significantly more sensitive to platinum-based chemotherapy than the high UCP2 expression group ( $\mathrm{P}=0.001$; Table IV).

Survival. The low UCP2 expression group showed significantly better overall survival compared with the high UCP2 expression group ( $\mathrm{P}=0.006$; Fig. 3).

Inhibition of UCP2 by genipin enhances the sensitivity of ovarian carcinoma cells to carboplatin. Expression of UCP2 mRNA in the ovarian serous carcinoma cell line OVSAHO was confirmed by real-time PCR. UCP2 expression in

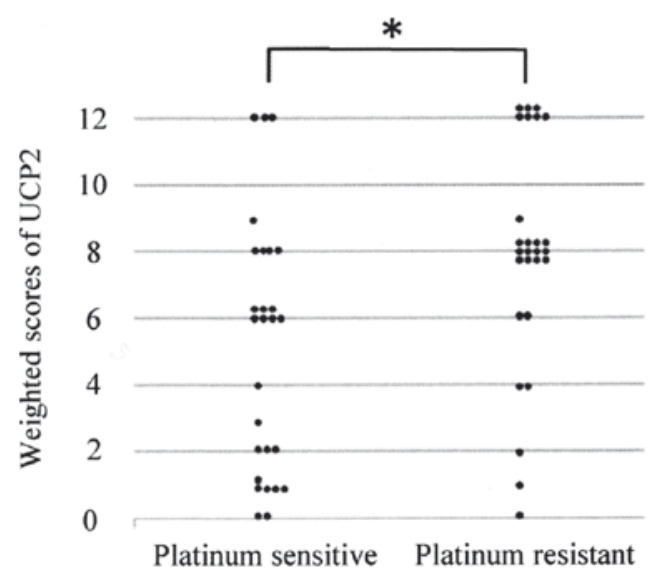

Figure 2. Weighted scores for UCP2 expression in tumor samples from patients with ovarian serous carcinoma. ${ }^{*} \mathrm{P}=0.005$ (Mann-Whitney U test). $\mathrm{UCP} 2$, uncoupling protein 2 .

OVSAHO cells was suppressed following $24 \mathrm{~h}$ of incubation with 10 or $50 \mu \mathrm{M}$ genipin (Fig. 4). Then, we examined whether the sensitivity of ovarian serous carcinoma cells to carboplatin was affected by treatment with genipin. Genipin-mediated inhibition of UCP2 expression in OVSAHO cells significantly enhanced their sensitivity to carboplatin (Fig. 5).

\section{Discussion}

UCP2 is widely expressed in cancer cells, and the expression of UCP2 is linked with ROS levels in various types of 
Table IV. Number of patients with low and high uncoupling protein 2 expression in the platinum-sensitive and -resistant groups.

\begin{tabular}{|c|c|c|c|}
\hline UCP 2 expression & Platinum sensitive, number (\%) & Platinum resistant, number $(\%)$ & P-value \\
\hline Low expression (score $\leq 6$ ) & $19(73.1)$ & $7(26.9)$ & $0.001^{\mathrm{a}}$ \\
\hline High expression (score $\geq 8$ ) & $8(28.6)$ & $20(71.4)$ & \\
\hline
\end{tabular}

${ }^{\mathrm{a}} \chi^{2}$ test

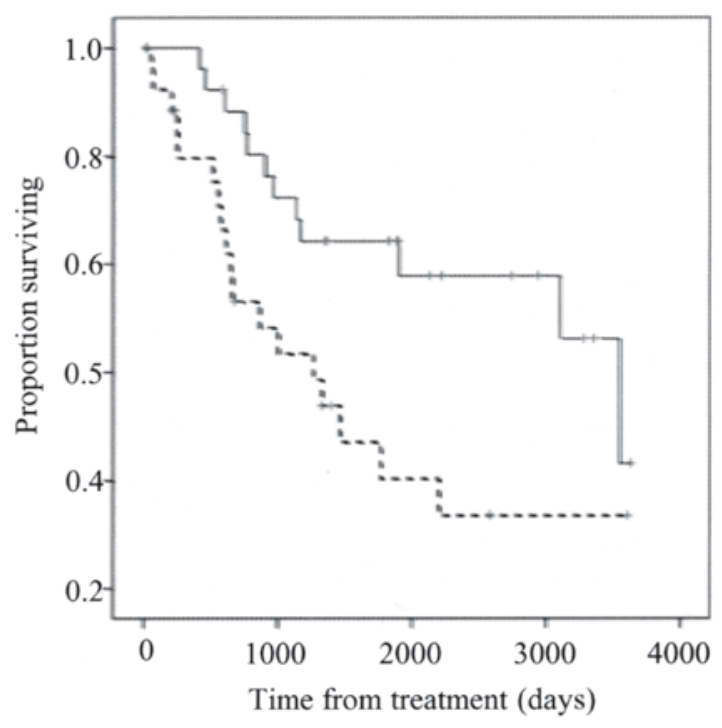

Figure 3. Overall survival rate in the low UCP2 expression (solid line; $\mathrm{n}=26$ ) and high UCP2 expression (broken line; $\mathrm{n}=28$ ) groups. $\mathrm{P}=0.006$ (Kaplan-Meier and log-rank tests). UCP2, uncoupling protein 2.

\section{2}

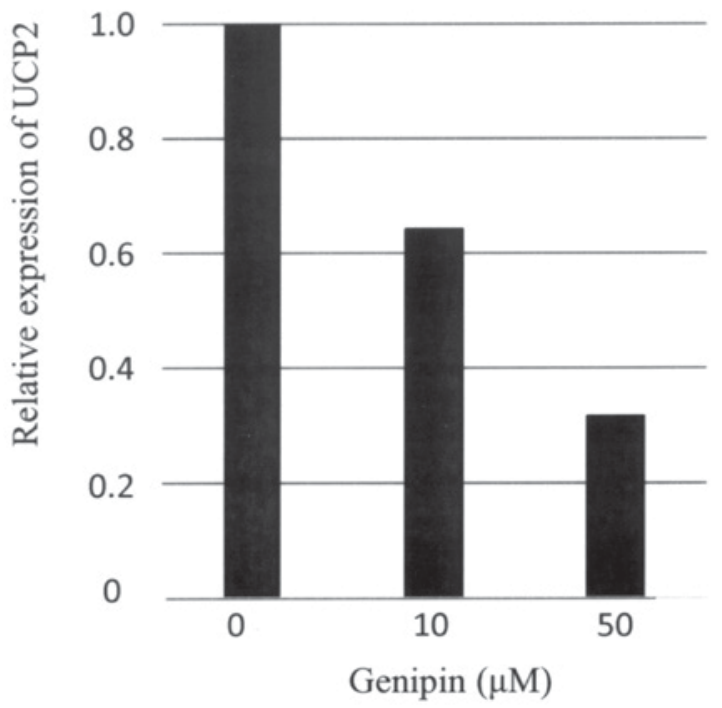

Figure 4. Relative expression of UCP2 in ovarian serous carcinoma OVSAHO cells, as confirmed by RT-qPCR of UCP 2 in these cells. UCP2, uncoupling protein 2 .

tissue (19,20). ROS production in cancer cells is inhibited through the expression of UCP2; therefore, high expression

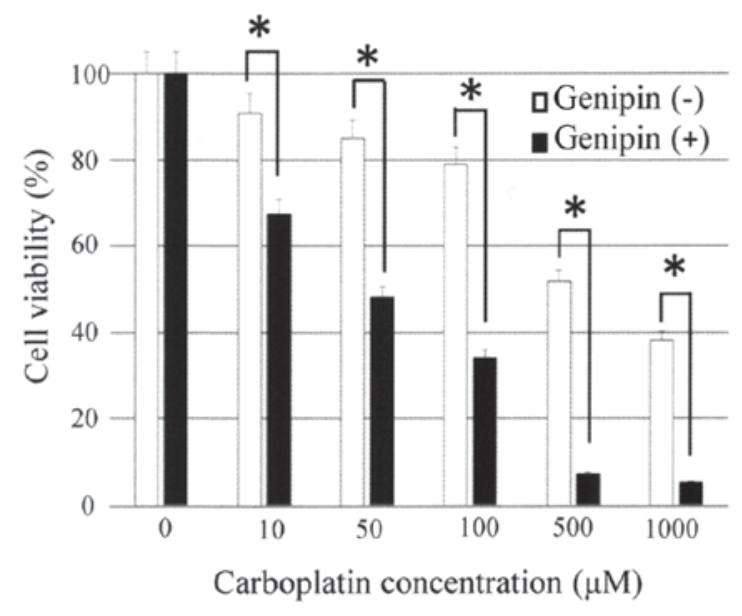

Figure 5. Sensitivity of OVSAHO cells to carboplatin in the presence or absence of genipin-mediated depletion of uncoupling protein 2. ${ }^{*} \mathrm{P}<0.05$ (Student's t-test)

of UCP2 can protect cells from oxidative stresses and cell damage $(22,23)$. UCP2 enhances both chemoresistance and carcinogenesis, and downregulation of UCP2 leads to increased cell death due to chemotherapy $(25,26)$.

This study shows a significant correlation between UCP2 expression and platinum sensitivity in patients with ovarian serous carcinoma. Patients with low UCP2 expression tended to be sensitive to platinum-based chemotherapy, and low UCP2 expression group showed significantly longer overall survival time than the high UCP2 expression group.

The present study demonstrated that the proliferation of OVSAHO cells was attenuated by the addition of genipin following administration of platinum agent. This is consistent with former reports using other cancer cells $(19,25,26)$. Moreover, these findings indicate that genipin can sensitize cancer cells to chemotherapeutic agents. The clinical application of genipin as a potential drug-sensitizing agent warrants further study.

These results suggest that UCP2 expression levels in patients with ovarian serous carcinoma are associated with the effectiveness of platinum-based chemotherapy. Therefore, UCP2 stands for a potential predictive marker of whether platinum based chemotherapy is likely to be effective in patients with ovarian serous carcinoma. Understanding the predictors of response to platinum-based chemotherapy can help us select patients sensitive to chemotherapy while sparing resistant patients from unnecessary toxicity of platinum-based chemotherapy, and also allows customization of treatments and clinical stratification of patients with ovarian cancer. 
In summary, UCP2 expression may be a predictive marker of the efficacy of platinum-based chemotherapy in patients with ovarian serous carcinoma. The present study is the first to demonstrate a correlation between UCP2 expression and platinum sensitivity. This knowledge can be great help to improve the prognosis of patients with ovarian serous carcinoma. We are planning further investigation regarding molecular mechanism.

\section{Acknowledgements}

The authors would like to thank Dr Mary Derry for editing a draft of this manuscript.

\section{Competing interests}

The authors declare that they have no competing interests.

\section{References}

1. Jemal A, Bray F, Center MM, Ferlay J, Ward E and Forman D: Global cancer statistics. CA Cancer J Clin 61: 69-90, 2011.

2. Borley J, Wilhelm-Benartzi C, Brown R and Ghaem-Maghami S: Does tumour biology determine surgical success in the treatment of epithelial ovarian cancer? A systematic literature review. Br J Cancer 107: 1069-1074, 2012.

3. du Bois A, Quinn M, Thigpen T, Vermorken J, Avall-Lundqvist E, Bookman M, Bowtell D, Brady M, Casado A, Cervantes A, et al: 2004 consensus statements on the management of ovarian cancer: Final document of the 3rd international gynecologic cancer intergroup ovarian cancer consensus conference (GCIG OCCC 2004). Ann Oncol 16: VII7-VI12, 2005.

4. Japan society of gynecologic oncology: Formulation committee of the treatment guidelines for ovarian. https://jsgo.or.jp/guideline/ransou2015.html. Accessed September 1, 2017.

5. Ozols RF, Bundy BN, Greer BE, Fowler JM, Clarke-Pearson D, Burger RA, Mannel RS, DeGeest K, Hartenbach EM and Baergen R; Gynecologic Oncology Group: Phase III trial of carboplatin and paclitaxel compared with cisplatin and paclitaxel in patients with optimally resected stage III ovarian cancer: A gynecologic oncology group study. J Clin Oncol 21: 3194-3200, 2003.

6. Friedlander M,TrimbleE,Tinker A, Alberts D,Avall-LundqvistE, Brady M, Harter P, Pignata S, Pujade-Lauraine E, Sehouli J, et al: Int J Gynecol Cancer 21: 771-775, 2011.

7. Markman M, Rothman R, Hakes T, Reichman B, Hoskins W, Rubin S, Jones W, Almadrones L and Lewis JL Jr: J Clin Oncol 9: 389-393, 1991.

8. Kyrgiou M, Salanti G, Pavlidis N, Paraskevaidis E and Ioannidis JP: Survival benefits with diverse chemotherapy regimens for ovarian cancer: Meta-analysis of multiple treatments. J Natl Cancer Inst 98: 1655-1663, 2006.

9. Pelicano H, Carney D and Huang P: ROS stress in cancer cells and therapeutic implications. Drug Resist Updat 7: 97-110, 2004.
10. Alexandre J, Batteux F, Nicco C, Chéreau C, Laurent A, Guillevin L, Weill B and Goldwasser F: Accumulation of hydrogen peroxide is an early and crucial step for paclitaxel-induced cancer cell death both in vitro and in vivo. Int J Cancer 119: 41-48, 2006.

11. Fruehauf J and Meyskens FL Jr: Reactive oxygen species: A breath of life or death? Clin Cancer Res 13: 789-794, 2007.

12. Boss O, Muzzin P and Giacobino JP: The uncoupling proteins, a review. Eur J Endocrinol 139: 1-9, 1998

13. Fleury $C$ and Sanchis D: The mitochondrial uncoupling protein-2: Current status. Int J Biochem Cell Biol 31: 1261-1278, 1999.

14. Baffy G: Uncoupling protein-2 and cancer. Mitochondrion 10: 243-252, 2010.

15. Echtay KS, Murphy MP, Smith RA, Talbot DA and Brand MD: Superoxide activates mitochondrial uncoupling protein 2 from the matrix side. Studies using targeted antioxidants. J Biol Chem 277: 47129-47135, 2002.

16. Duval C, Nègre-Salvayre A, Dogilo A, Salvayre R, Pénicaud L and Casteilla L: Increased reactive oxygen species production with antisense oligonucleotides directed against uncoupling protein 2 in murine endothelial cells. Biochem Cell Biol 80: 757-764, 2002.

17. Mattiasson G, Shamloo M, Gido G, Mathi K, Tomasevic G, Yi S, Warden CH, Castilho RF, Melcher T, Gonzalez-Zulueta M, et al: Uncoupling protein-2 prevents neuronal death and diminishes brain dysfunction after stroke and brain trauma. Nat Med 9: 1062-1068, 2003.

18. Teshima Y, Akao M, Jones SP and Marban E: Uncoupling protein-2 overexpression inhibits mitochondrial death pathway in cardiomyocytes. Circ Res 93: 192-200, 2003.

19. Horimoto M, Resnick MB, Konkin TA, Routhier J, Wands JR and Baffy G: Expression of uncoupling protein-2 in human colon cancer. Clin Cancer Res 10: 6203-6207, 2004.

20. Carretero MV, Torres L, Latasa U, Garcia-Trevijano ER, Prieto J, Mato JM and Avila MA: Transformed but not normal hepatocytes express UCP2. FEBS Lett 439: 55-58, 1998.

21. Imai K, Fukuda T, Wada T, Kawanishi M, Tasaka R, Yasui T and Sumi T: UCP2 expression may represent a predictive marker of neoadjuvant chemotherapy effectiveness for locally advanced uterine cervical cancer. Oncol Lett 14: 951-957, 2017.

22. Derdák Z, Fülöp P, Sabo E, Tavares R, Berthiaume EP, Resnick MB, Paragh G, Wands JR and Baffy G: Enhanced colon tumor induction in uncoupling protein-2 deficient mice is associated with NF-kappaB activation and oxidative stress. Carcinogenesis 27: 956-961, 2006.

23. Collins P, Jones C, Choudhury S, Damelin L and Hodgson H: Increased expression of uncoupling protein 2 in HepG2 cells attenuates oxidative damage and apoptosis. Liver Int 25: 880-887, 2005.

24. Sinicrope FA, Ruan SB, Cleary KR, Stephens LC, Lee JJ and Levin B: Bcl-2 and p53 oncoprotein expression during colorectal tumorigenesis. Cancer Res 55: 237-241, 1995.

25. Dalla Pozza E, Fiorini C, Dando I, Menegazzi M, Sgarbossa A Costanzo C, Palmieri M and Donadelli M: Role of mitochondrial uncoupling protein 2 in cancer cell resistance to gemcitabine. Biochim Biophys Acta 1823: 1856-1863, 2012.

26. Mailloux RJ, Adjeitey CN and Harper ME: Genipin-induced inhibition of uncoupling protein-2 sensitizes drug-resistant cancer cells to cytotoxic agents. PLoS One 5: e13289, 2010 